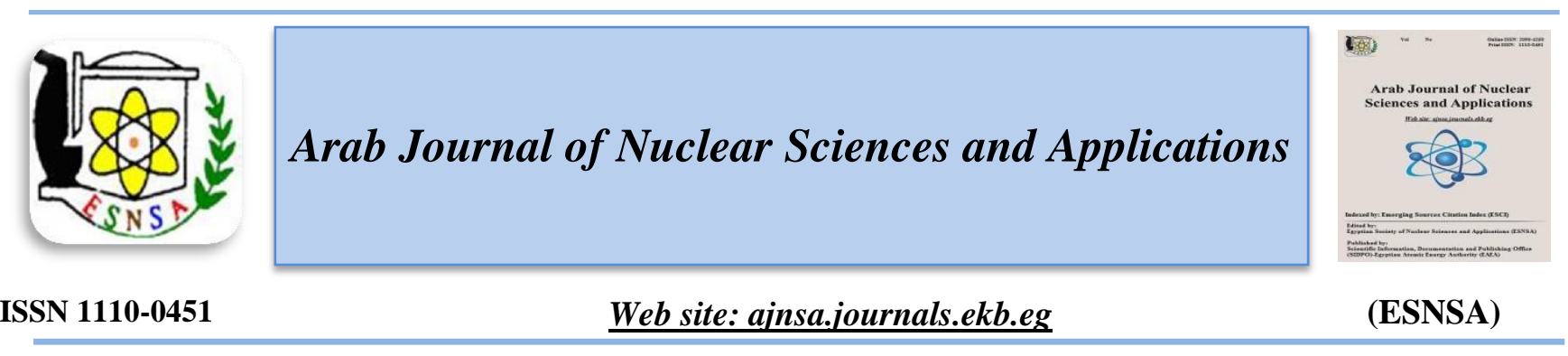

\title{
Stresses Induced by LOCA in Steam Generator Collector of the VVER1000 Reactor
}

\author{
Dina Ali Amer ${ }^{1}$, Nikonov S.P. ${ }^{2}$, Azza A. Hassan ${ }^{3}$, Khaled H. Ahmed $^{4}$ \\ ${ }^{(1)}$ National Research Nuclear University "MEPhI", Moscow, Russia, Alexandria University, Egypt \\ (2) National Research Nuclear University "MEPhI", Moscow, Russia \\ ${ }^{(3)}$ Department of Nuclear fuel cycle Safety, Egyptian Nuclear and Radiological Regulatory Authority \\ (ENRRA), Cairo, Egypt \\ ${ }^{(4)}$ Department of Nuclear fuel cycle Safety, Egyptian Nuclear and Radiological Regulatory Authority \\ (ENRRA), Cairo, Egypt
}

\begin{abstract}
Received 3 Feb. 2020 Accepted 14 Apr. 2020

During Double End Break Loss of Coolant Accident (DEBLOCA) in theVVER-1000 reactor, in the first second, pressure waves had been noticed in all points hitting the main components of the primary cooling circuit. Studying the stresses due to DEBLOCA is important to avoid equipment failure. The main attention is focused on the pressure drops on the equipment, because this parameter determines the dynamic loads on the equipment, which can lead to its failure. ATHLET code is used to obtain pressure and temperature variation with time during the accident for the VVER1000 reactor Kalinin-3. The results are used in ANSYS finite element package to calculate stresses in the steam generator collector. The stress, just before the emergency (at time $0.014 \mathrm{sec}$ ), was $4.3 \mathrm{E}+7$ pa and became $4.38 \mathrm{E}+6$ pa just after the emergency (at time 0.022 second). Fluctuations appear with two peaks of highest amplitude of $1.87 \mathrm{E}+7$ and $2.38 \mathrm{E}+7$ pa at time of 0.06 and 0.094 sec respectively, which is well belowthe allowable stress. The results indicate the safe operation of the equipment.
\end{abstract}

Keywords: VVER1000 / LOCA / Steam Generator Collector / Stresses

\section{Introduction}

The occurrence of pressure waves and their propagation in the equipment of the primary circuit of the VVER-1000 reactor plant in emergency situations, associated with an instantaneous twoway flow with an instantaneous two-way break in the cold thread of the main circulation pipeline, has been studied [1-2].

The influence of the time of initialization of the accident on the intensity of the process-amplitude and frequency of pressure changes was investigated. Pressure drops during an emergency on the main elements of the circuit was presented.
It was shown that the maximum changes in the amplitude and frequency of both the pressure and the pressure drop on the circuit elements belong to the initial stage of the accident. The main attention is focused on the pressure drop on the equipment, because this parameter determines the dynamic loads on the equipment, which can lead to its failure.

Germany and certified in Russia for use in calculations to justify the safety of reactors with water coolant [5].

In the present paper, a study for the consequence stress on the steam generator in the first loop of the

Corresponding author: Azzaaea@yahoo.com

DOI: 10.21608/ajnsa.2020.22763.1325

CScientific Information, Documentation and Publishing Office (SIDPO)-EAEA 
primary circuit is considered. Finite Element package (ANSYS) is used to obtain stresses on the upper part of the cold collector. A three-dimension model is used to simulate this part.

\section{Accident scenario:}

At the first stage of modeling, the specified parameters are used by specially designed regulators. At the second stage, when specially designed regulators are disabled and real nuclear power plant regulators are used, and already use them to maintain the necessary stationary conditions with the parameters set before the transition process in the installation objects: pressures, levels, temperatures, power, etc.

Only after maintaining a certain period of the necessary stationary state, the transition process begins, caused by modeling double end break LOCA.

First, a normal operation for 1000 seconds was considered and then within 10E-4 second a complete break "double end $80 \%$ of the crosssection area" is considered in location L4.

\section{Explanation of the task}

The work presented in this paper is a part of multistep research which is done as follows:

1. Studying the situation of instant stop of the MCP (Main Circulation Pump) in the first loop of the primary coolant circuit. we assume an instant stop of the pump, its jamming, that is, the pump blades do not turn. In this case, the flywheel of the motor is disconnected from the pump shaft. The program has the ability to simulate a similar pump stop[2]

2. Considering LOCA (Loss of Coolant Accident) (DEB "Double End Break") in the first loop of the primary coolant circuit near to the core entrance (Location. "L1"), shown in Figure (1) [6]

3. Comparing the two emergency situations from the point of view of the consequence pressure waves in the main components of the reactor. [7,8]

4. Analysis of uncertainty in the concept of "instantaneous" in the calculation of emergency modes. Five different gaps of time were considered for both emergency cases. [9]

5. LOCA in different locations in the first loop of the primary circuit: 6 locations (shown in Figure 1) for LOCA were considered in this step.[10]

6. The most dangerous places of LBLOCA (Large Break Loss of Coolant Accident) in the four loops of primary coolant circuit as a source of dynamic load on the equipment: The six locations in step 5 were considered in each loop. [11]

7. The effect of reactor power behavior on LBLOCA hydrodynamics. [12]

The most important common conclusion for this study was: The initial period of the accident is considered in detail because the strongest amplitude and frequency of pressure fluctuations on NPP elements is occurred, which can lead to significant dynamic loads on the structural elements of these objects. This can be estimated either by the joint strength and hydrodynamic calculations, or by the possible use of the results obtained in this study as boundary conditions for the calculation of dynamic loads. This situation was the same considering 6 different locations for the DEBLOCA, as sown in Figure (1).

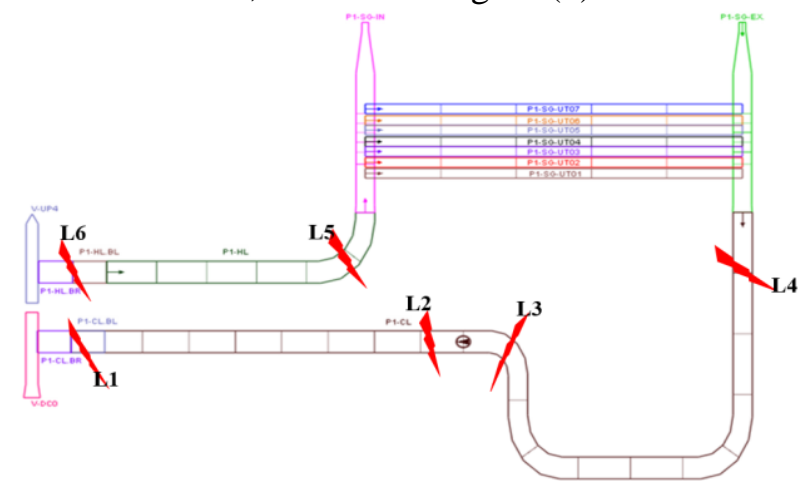

Fig.(1): The six studied locations for DEBLOCA

\section{A Brief Description of the calculation code ATHLET}

The thermo hydraulic system code ATHLET (Analysis of Thermal-hydraulics of LEaks and Transitions) was developed in plant and reactor safety society(GRS $\mathrm{mbH}$ ) and was originally intended for analysis of the entire spectrum of leak and transient analyses in PWR and BWR reactors. However, experience with this approach has shown that it can be successfully used to the full extent for Russian reactors such as VVER and RBMK. ATHLET consists of several basic modules that allow describing different phenomena in the behaviourof thermal hydraulic systems. These are thermal hydraulic module (TFD), heat exchange 
and thermal conductivity module (HECU), neutron-kinetic module (NEUKIN) to describe point and one-dimensional kinetics, module to describe the operation of the equipment (GCSM) and fully implicit module for numerical integration (FEBE). Other independent modules can be connected via the main interface.

The TFD module is based on the use of five or six equations (the General equation for the moment of motion of the mixture with the drift flow) to describe the two-fluid model. In addition to light water, the module allows calculations with other types of reactor coolants, such as: heavy water, liquid metals (lead, lead-bismuth, sodium), gases (helium). The module also simulates the behavior of non - condensable gases (air, nitrogen, argon, hydrogen, helium, oxygen, user gas-when the user sets its properties), nitrogen dissolution and describe the transport of boron in systems with light and heavy water.

The plant cooling system is modeled by connection of the basic thermodynamic objects (TFO). Besides, there is a special possibility for calculation of cross flows in system of the parallel connected channels. Quite widely used capabilities of the ATHLET code, for linking with various three-dimensional neutron-physical programs in the calculation of the spatial distribution of energy release fields and the spatial distribution of the coolant parameters in the reactor core (up to the sub-cassette), are presented in several previous publications[13-18].

\section{VVER1000 steam generator}

The steam generator is the point where the water (coolant) from the primary (irradiated) circuit and the water from the secondary cooling circuit (clean) are contracted, but not mixed (just for a heat exchange). The structure and dimensions of the VVER-1000 steam generator is shown in Figure (2).

The point where the two cooling circuits are connected is where the steam generator linked the primary and secondary cooling water is shown in Figure (2).The upper part (cone-shaped) which is used in the finite element model to calculate the stresses included in the steam generator collector, is shown in Figure (2b).

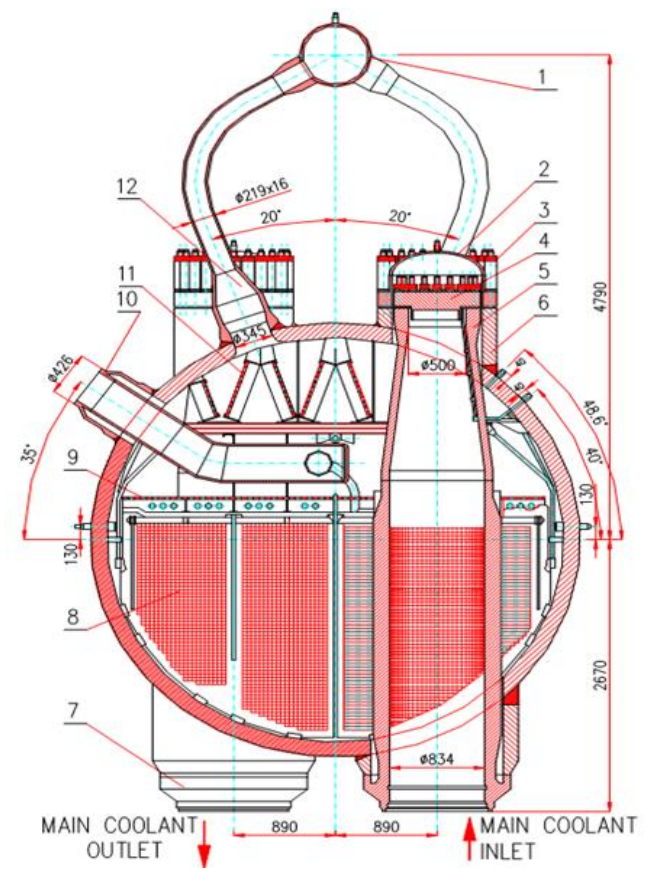

(a)

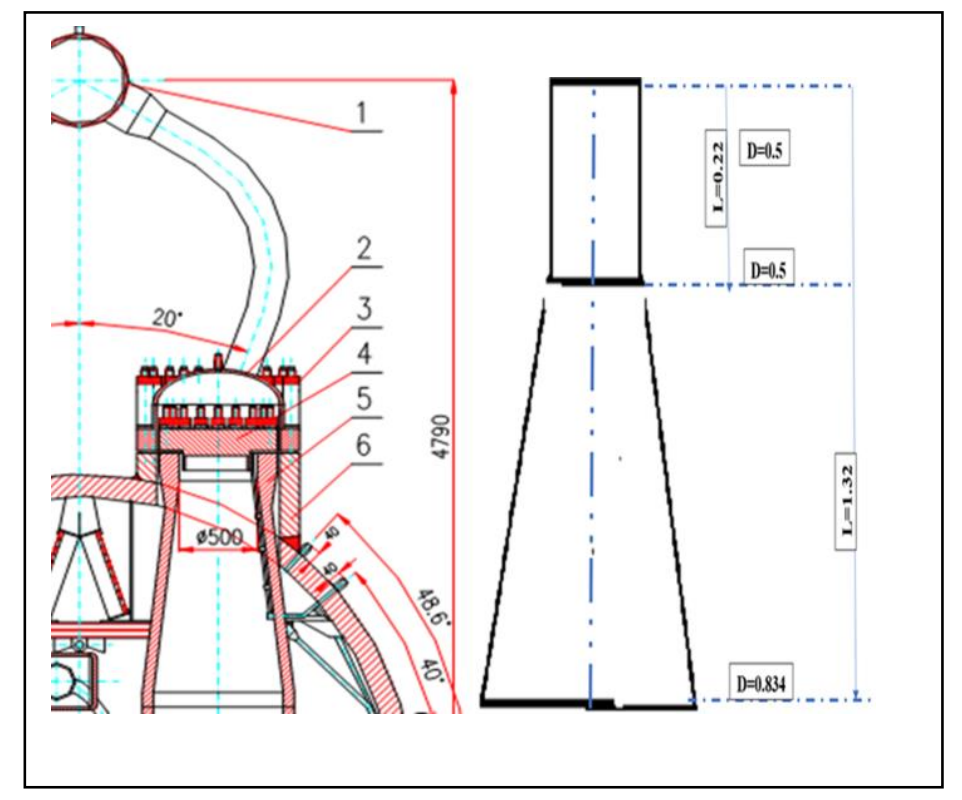

(b)

Fig. 2: (a):VVER1000 steam generator (1- Steam Header 2- Secondary Circuit (SC) Header Cover 3- Nuts 4- Primary Circuit (PC) Header Cover 5- SC Header 6- PC Header 7- MCC Nozzle 8- Heat Exchange Tubes 9- Steam Pressure Equalization Unit 10-Feedwater Nozzle 11-Separation Units 12-Steam Nozzle) (b): Enlargement of the Upper (cone-shaped) Part of the Collector and its Cover 
Finite element model description

In the present work, a three-dimension structural model for the upper part of the cold collector using ANSYS Finite Element (FE) package is used. Stress distribution with time through the simulated part under DEBLOCA condition of the VVER1000 reactor are obtained.

The boundary conditions of the structural analysis are as follows:

- External pressure: The fluid pressure in the accident scenario (red line in Fig. (5),steam generator secondary circuit side (S1-UP))perpendicular to the surface

- Internal pressure: The fluid pressure in the accident scenario (upper line in Fig. (5),exit point (P1-SG-EX) of steam generator collector) perpendicular to the surface

- Steam environment temperature: $277^{\circ} \mathrm{C}$

- The base of the simulated part is fixed support

The output results from the ATHLET code for temperature and pressure are utilized as input loads to the ANSYS structural module. A time period of one second is simulated with the same step of ATHLET code. The model has 26205 elements. Refinement by degree of three is done for the upper part of the model. The mesh element is shown in Figure (3).

The material of the steam generator collector is the Russian alloy 10GN2MFA [19].

The mechanical properties of the 10GN2MFA steel are represented in table 1.

Table (1): 10GN2MFA steel properties used in FE model (at $350^{\circ} \mathrm{C}$ )

\begin{tabular}{lc}
\hline Density $\left(\mathrm{kg} / \mathrm{m}^{3}\right)$ & 8050 \\
\hline Coefficient of thermal expansion & $1.2 \mathrm{e}-5$ \\
$\left({ }^{\circ} \mathrm{C}^{-1}\right)$ & 490 \\
Tensile strength (MPa) & 295 \\
Conditional Yield Strength (MPa) & 0.3 \\
\hline
\end{tabular}

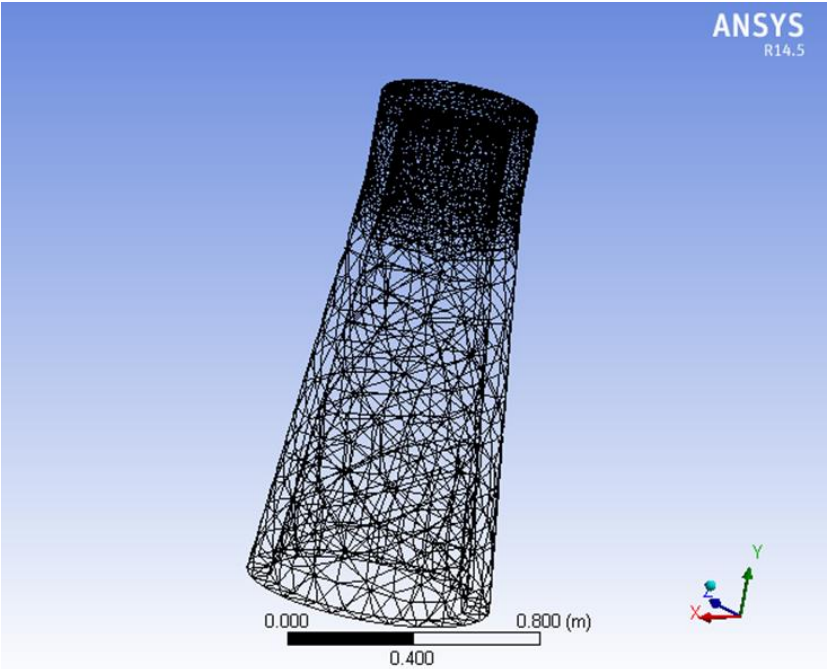

Fig.(3): Mesh element of the structural module

\section{Results and Discussion}

ATHLET results

The maximum pressure dropin the case of DEBLOCA was observed in location L5 for the hot collector, and L4 for cold collector. The point L4, as shown in Figure (5), can be considered as the most dangerous location point in case of DEBLOCA in the point of view of the consequent pressure waves.

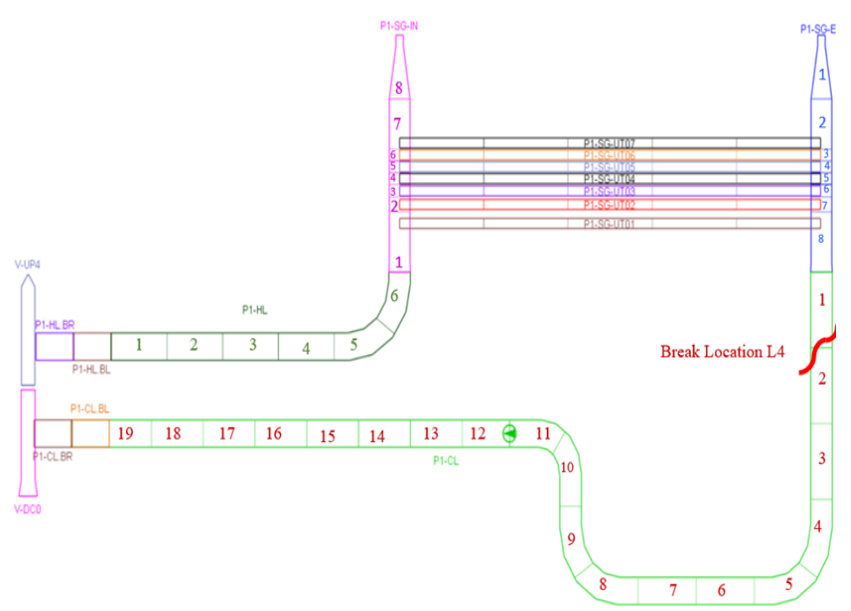

Fig.(4): The considered DEBLOCA location for current study

Figure (5) illustrates the Pressure changes with time in the exit point (P1-SG-EX) of steam generator collector, Inlet point (P1-SG-IN) of steam generator collector, and steam generator secondary circuit side (S1-UP).

The maximum fluctuation for the pressure is noticed in the steam generator exit point. The pressure in the exit point of the steam generator 
collector was $15.3 \mathrm{E}+6 \quad \mathrm{~Pa}$ just before the emergency (at time $=1000.004$ second) and drops to $5.5 \mathrm{E}+6 \mathrm{~Pa}$ just after the emergence (at time $=1000.022$ second), where the pressure in the inlet point of the steam generator was $15.4 \mathrm{E}+6 \mathrm{~Pa}$ just before the emergency (at time $=1000.004$ second) and drops to $8.7 \mathrm{E}+6 \mathrm{~Pa}$ after the emergency (at time $=1000.012$ second).

The temperature change with time in ${ }^{\circ} \mathrm{C}$ in the exit point (P1-SG-EX) of the steam generator collector, in the Inlet point, (P1-SG-IN) of steam generator collector, and steam generator secondary circuit side (S1-UP) are shown in Figure (6). It is noticed that the temperature at the inlet point of the steam generator was $279^{\circ} \mathrm{C}$ (at time $=1000.002$ second) and become $299^{\circ} \mathrm{C}$ (at time $=1000.013$ second), whereas the temperature at the exit point was $279^{\circ} \mathrm{C}$ before the emergency (at time $=1000.01$ second) and drops to $\sim 275^{\circ} \mathrm{C}$ (at time $=1000.022$ second) after the emergency.

The instantaneous change in the pressure and temperature with the strongest amplitude and frequency are considered a source of dynamic loads on the structural elements of these objects.

\section{Finite Element Results}

The equivalent stress [20] $\left(\sigma_{\mathrm{e}}\right)$ is related to the principal stresses by the following equation:

$$
\sigma_{\mathrm{e}}=\sqrt{\frac{(\sigma 1-\sigma 2)^{2}+(\sigma 2-\sigma 3)^{2}+(\sigma 3-\sigma 1)^{2}}{2}}
$$

The principal (normal) stresses $(\sigma 1, \sigma 2, \sigma 3)$ are always ordered such that $\sigma 1>\sigma 2>\sigma 3$.

Von Mises equivalent stress is obtained through the first second during DEBLOCA. Stress fluctuations due to accidents indicate how the safety factor should be chosen to compensate for abnormal sudden change conditions.

The sudden change in the pressure and temperature with the high amplitude and frequency are considered a source of severe dynamic load. Dimensions, materials, and design of the equipment are highly sensitive to generated stress level due to accident conditions.

The dominant Von Mises stress during the analysis time, shown in Figure (7), is well below the allowable stress (295 MPa), which means that the case is in safe operation of the equipment. The upper and lower lines in Figure (7) present maximum and minimum stress variation with time respectively.

The stress just before the emergency (at time 0.014 sec) was 4.3E+7Paand becomes $4.38 \mathrm{E}+6$ Pajust after the emergency (at time $=0.022$ second). Fluctuations appear with two peaks of highest amplitude of $1.87 \mathrm{E}+7$ and $2.38 \mathrm{E}+7$ paat time of0.06 and $0.094 \mathrm{sec}$ respectively.

Even though the pressure fluctuations are not accompanied by stresses exceed the allowable stress, the pressure fluctuations can cause fatigue seed which may cause future failure. It is highly recommended to study fatigue due to such accidents.

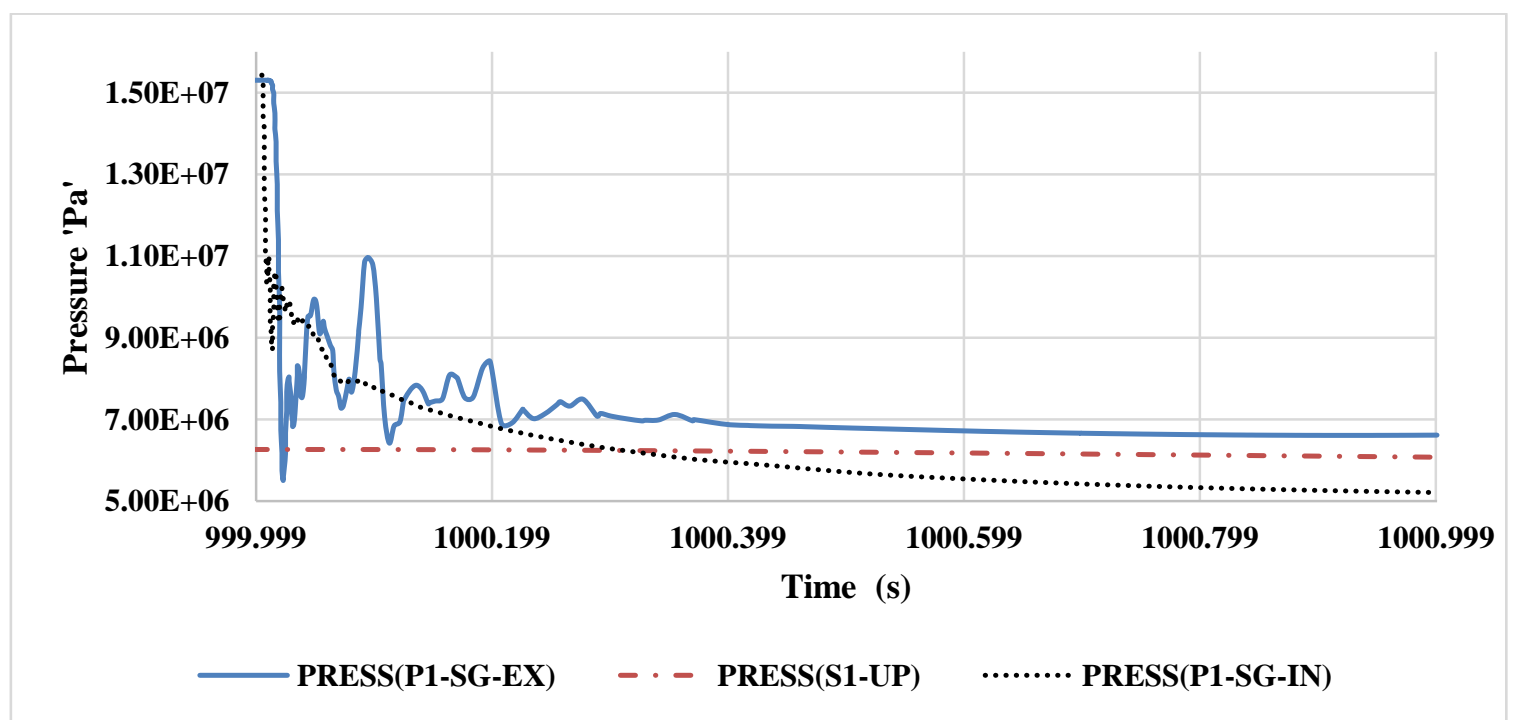

Fig. (5): Pressure change with time in: the exit point (P1-SG-EX) of steam generator collector, the Inlet point (P1-SG-IN) of steam generator collector, and steam generator secondary circuit side (S1-UP) 


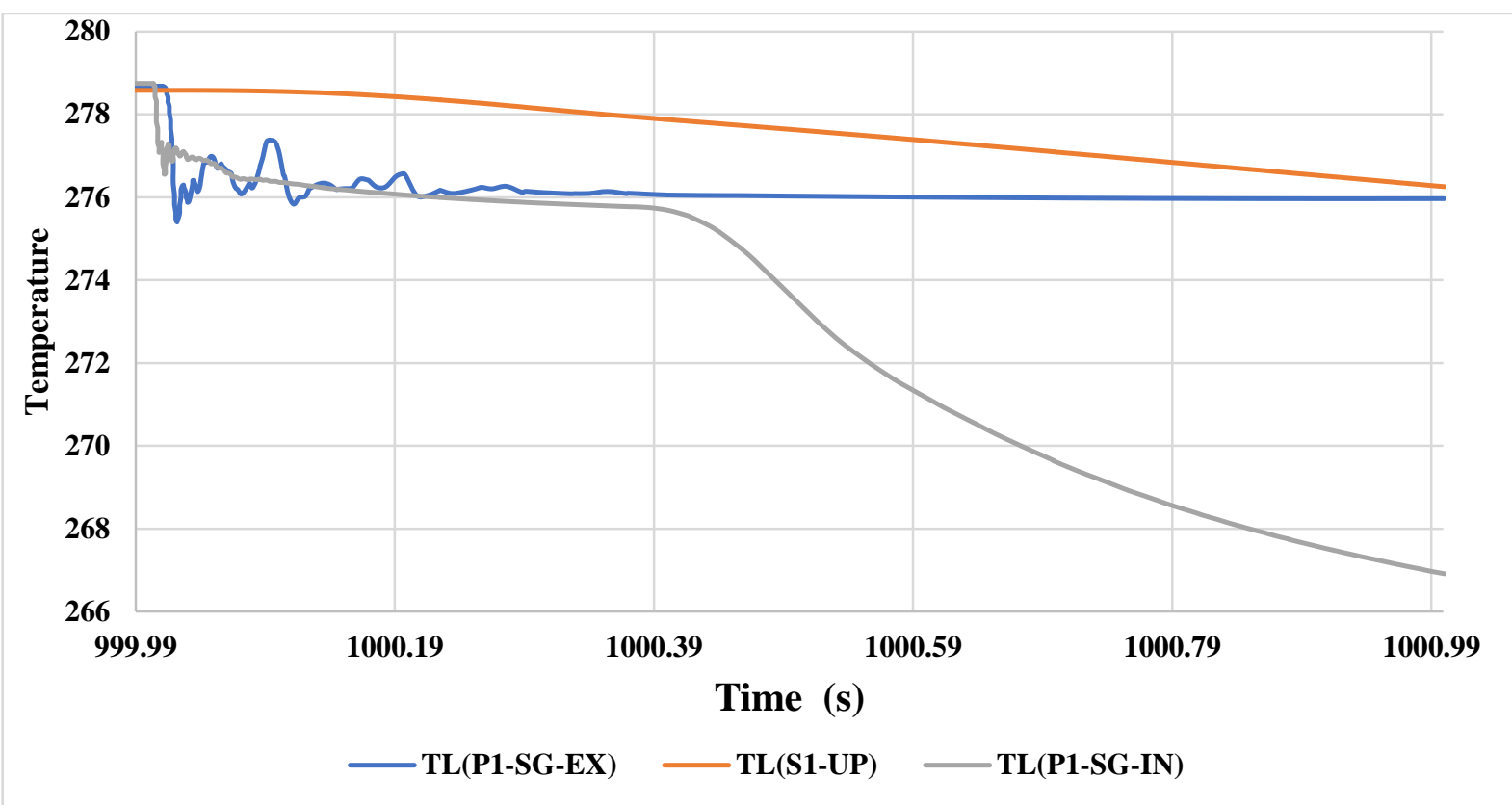

Fig.(6): Temperature change with time in: the exit point (P1-SG-EX) of steam generator collector,the Inlet point

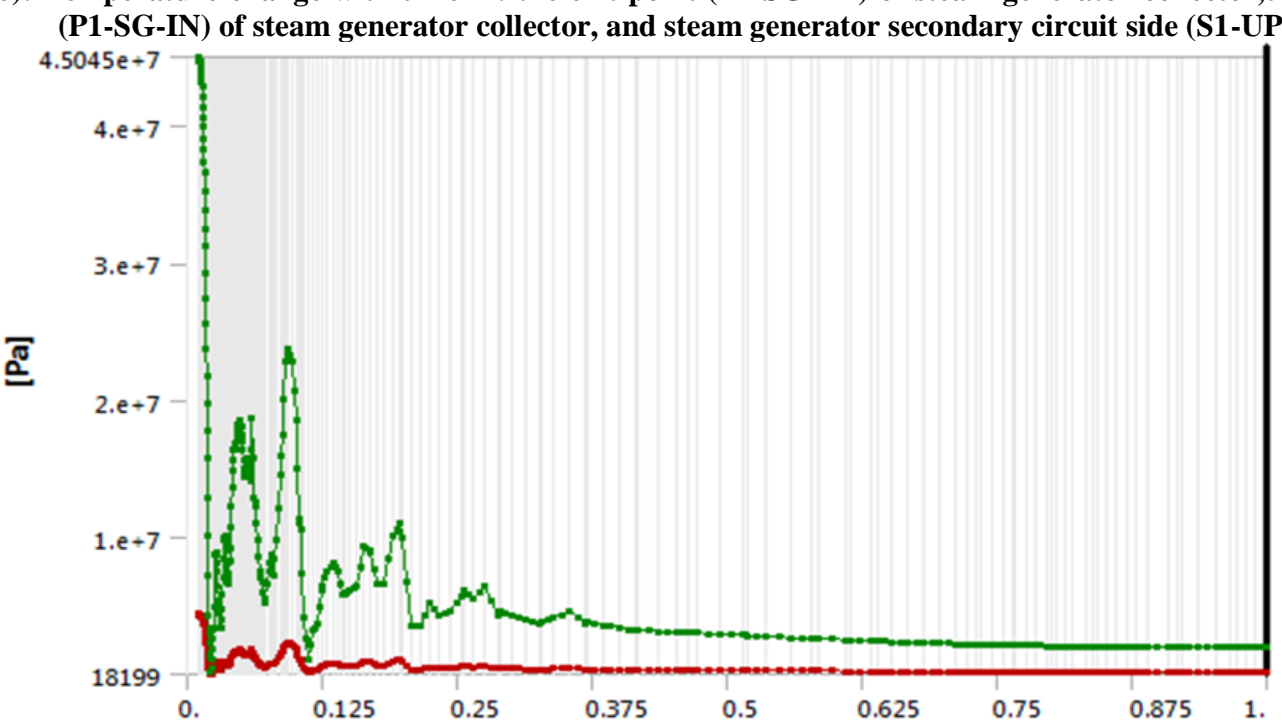

[s]

Fig.(7): Von MisesStress variation with time

\section{Conclusion}

The initial period of the accident is analysed in detail because the high amplitude and frequency of pressure fluctuations on NPP elements have occurred, which can lead to significant dynamic loads on the structural elements of collector. The results obtained in the first part of the present work are considered as boundary conditions for the calculation of dynamic loads. Through the present work, a three-dimension model is used inANSYS finite element package to simulate the upper part of the cold collector were the maximum pressure waves is occurred during the accident. Stresses on the simulated part are evaluated and explained. The results reflect the high safety factor of the design area in such severe accident. The maximum generated Von Mises stress is in the order of 23.8 MPa which is far away from the yield point of the operating steel which is $295 \mathrm{MPa}$. 


\section{References}

1. PNAE G-1-036-95 (NP-006-98)with Change No. 1(2005)Requirements to the Content of the Report on the Justification of the Safety with a VVER Type Reactor.

2. Dina Ali Amer, and Nikonov S.P. (2018) Pressure Waves in The Primary Circuit of the VVER - 1000 Reactor at Instant Stop of the MCP, International Conference for Young Scientists, Specialists, and Post-Graduates on Nuclear Reactor Physics,

3. V. A. Tereshonok, S.P. Nikonov, M. P. Lizorkin, K. Velkov, A. Pautz, andK. Ivanov(2008) International Benchmark for Coupled Codes and Uncertainty Analysis in Modelling: Switchingoff of One of the Four Operating Main Circulation Pumps at Nominal Power at NPP Kalinin Unit, 18th Symposium of AER on VVER Reactor Physics and Reactor Safety, Hungary, Eger.

4. H. Austregesilo, H. Deitenbeck, A. Langenfeld, J. Scheuer, and P. Schöffel (March 2017)ATHLET 3.1A, programmer's Manual.

5. Rostexnadzor, FBU «NTC YARB» (2014)Certifiacation Pasport Software 350, Russian.

6. Dina Ali Amer, and Nikonov S.P. (October 8-12, 2018) LOCA and Pressure Waves in The First Loop of the VVER-1000 Reactor, $28^{\text {th }}$ Symposium of AER on VVER Reactor Physics and Reactor Safety, Olomouc, Czech.

7. Dina Ali Amer, and Nikonov S.P.(22-26 October 2018). Emergency Situations and Pressure Waves in VVER-1000, The Sixth International Conference of Radiation Sciences and Applications, Ibis Dahab, Egypt.

8. Dina Ali Amer, and Nikonov S.P. (2019) Comparing the Consequences Pressure Waves due to MCP Pump Stops and LOCA in VVER1000, Journal of the National Research Nuclear University"MIFI", 8(4), 309-320.

9. Dina Ali Amer, and Nikonov S.P. (2018) Analysis of Uncertainty in the Concept of "Instantaneous" in the Calculation of Emergency Modes, XIV International Youth Scientific and Practical Conference "The Future of Nuclear Energy - Atom Future 2018" Obninsk, Kaluga region, Russia.

10. Dina Ali Amer, Nikonov S.P.(April 10-11, 2019). Analysis for Pressure Waves in VVER1000 Due to LOCA in Different Locations, the $21^{\text {st }}$ international Conference of Young
Specialists in Nuclear Power Plants. Moscow, Russia.

11. Dina Ali Amer, and Nikonov S.P.The First Circuit of VVER-1000 and the Most Dangerous Places of LBLOCA as a Source of Dynamic Load on the Equipment, 11th international scientific and technical conference "Safety of nuclear power plants with VVER", Podolsk, Moscow, Russia.

12. Dina Ali Amer, and Nikonov S.P.(11-12 November 2019). The Effect of Reactor Power Behavior on LBLOCA Hydrodynamics, VVER2019 Conference, Prague, Czech.

13. Grundmann U., Lucas D., and Rohde U (1995). Coupling of the Thermohydraulic Code ATHLET with the neutron kinetic core model DYN3D. In: Proc. of Int. Conf. on Mathematics and Computations, Physics and Environmental Analysis, Portland (USA), 1, 257-263.

14. Panka I, Hegyi G Y, Maráczy Cs and Keresztúri K (Oct.13-16, 2015). Uncertainties of the Kiko 3D- ATHLET Calculations using the Kalinin-3 Benchmark (phase II) Data, 25th Symposium of AER on VVER Reactor Physics and Reactor Safety, Hungary, Balatongyörök.

15. Nikonov S., Pautz A., and Velkov K. (May 8-12, 2011). Detailed modeling of Kalinin-3 NPP VVER-1000 Reactor Pressure Vessel by the Coupled System Code ATHLET/BIPR-VVER, Int. Conf. on Mathematics and Computational Methods Applied to Nuclear Science and Engineering, (M\&C 2011), ISBN 978-85-6368800-2, Rio de Janeiro, RJ, Brazil.

16. Romanenko V, Bachdanovich R, Bogdanova E, Nikonov $S$ and Tikhomirov G(Oct. 2017). Complex Modeling Of VVER-1000 Fuel Assembly Using Codes MCU/ATHLET, 27th Symposium of AER on VVER Reactor Physics and Reactor Safety, Munich, Germany.

17. Nikonov S, Pham P, Romanenko V and Tikhomirov G (Oct. 2017).Coupled NeutronicsThermohydraulic Calculation of HPLWR Fuel Cell Using Codes MCU/ATHLET, 27th Symposium of AER on VVER Reactor Physics and Reactor Safety, Munich, Germany.

18. Danilin S, Nikonov S, Lizorkin M and Krukov S (RRC KI, Russia) (September 22-26, 2003) Comparative Analysis of Consistent Coast-Down of One of Four and One of Three Working Main Circulation Pumps with ATHLET/BIPR8KN and TIGER-1, $13^{\text {th }}$ Symposium of AER on VVER Reactor Physics and Reactor Safety, Dresden, Germany. 
19. V. p. Denisov, and Yu. g. Dragunov (2002).VVER Reactor Installations for Nuclear Power Plants, art. 447
20. ANSYS workbench user manual. (2007)version 11. Providence RI, USA. 